\title{
Dural adhesion as a cause of late clip slippage from the medial cerebral artery aneurysm
}

\author{
T. Szmuda, P. Słoniewski \\ Neurosurgery Department, Medical University of Gdansk, Poland \\ [Received: 9 December 2018; Accepted: 3 January 2019]
}

Background: A properly placed clip may slip off the aneurysm during the postoperative period. Many factors have been attributed to this complication, although clip adherence to the dural stitch has not been reported.

Materials and methods: Following the single occurrence of such unusual complication, 64 similar medial cerebral artery (MCA) aneurysms were retrospectively investigated at a single institution. Clip adherence to the dura demonstrated in early postoperative computed tomography (CT) was a presumed factor of a late clip migration in this study.

Results: In the series, there were 4 (6.3\%) aneurysm remnants and 1 slipped clip that firmly adhered to the dura. In this particular case, the revision surgery revealed the spring coil firmly adhering to the dura in the previous suture line. Neither the occurrence of an aneurysm neck remnant nor clip slippage were related to the clip's adherence to the dura in the analysis of the entire group $(p>0.05)$. On the contrary, application of a fenestrated clip did contribute to that finding in multivariate analysis $(p<0.01)$. Unlike the rest, two surgeons unintentionally tended to position the clip close to the dura $(p<0.01)$. The clip-to-dura distance measured in the follow-up CT angiography 1 year after the surgery differed from that in the postoperative CT in $83.8 \%$ of the cases and decreased by an average of $0.5 \mathrm{~mm}$.

Conclusions: Clip-to-dura adherence should be regarded as a normal finding in the postoperative CT following MCA aneurysm clipping. Surgeons should consider the possibility of clip head protrusion into the dural stitch line. (Folia Morphol 2019; 78, 3: 501-507)

Key words: intracranial aneurysm, cerebral aneurysm, clip slippage, medial cerebral artery, neurosurgical clipping

\section{INTRODUCTION}

Total occlusion of a cerebral aneurysm is the ultimate goal of surgical clipping. An intraoperative clip slippage is occasionally observed and is usually attributed to inappropriate use of short-bladed clip, metal alloy features or weak closing pressure of an older generation clip $[8,11]$. Intraoperative clip exchange or its correction is usually sufficient. Most operators prefer to use a single clip, although placing several clips along the neck of larger aneurysm is considered a more durable solution [21]. However, either a collapsing dome of the aneurysm after clipping or correct clip placement seen on postoperative imaging does not guarantee long-term success. To resist slippage, the aneurysm clips are produced with corrugated jaws, which nevertheless sometimes are insufficient. Since the first case of patient's death as a result of late clip slippage was published, authors

Address for correspondence: Dr. T. Szmuda, Neurosurgery Department, Medical University of Gdansk, ul. Dębinki 7, 80-952 Gdańsk, Poland, tel: +48 5834923 30, fax: +48 5834558 88, e-mail: tszmuda@gumed.edu.pl; pslonie@gumed.edu.pl 
demonstrated various examples of late clip migration following apparently successful operations [17]. One report described a clip head trapped between optic nerves, while in other case it was found distally in the sacral subarachnoid space $[12,16,20]$. General$l y,<1 \%$ of follow-up angiograms reveal displaced clips, including the cases with fatal outcomes [3]. The reasons for clip slippage were mostly attributed to inappropriate clip material (originally weak closing forces, material fatigue, influence of resterilisation), aneurysm shape (incomplete occlusion, wide or calcified neck) and arterial pulsative forces [7, 9, 22]. Although various manoeuvres how to avoid late clip slippage were suggested, the authors predominantly focused on the factors related to the particular patient or the operative circumstances. The existing knowledge about the causes of a clip slippage remains dispersed among numerous case reports. However, it seems no literature related the adherence of a clip to the dura observed in a postoperative image to the clip slippage phenomena.

We encountered an unusual case of postoperative clip slippage in which we suspected either dural adhesions, unintended iatrogenic suturing of the clip or its trapping in a suture gap. Thus, we hypothesized that adherence of a clip to the dura could be regarded as a finding contributing to postoperative clip slippage.

\section{MATERIALS AND METHODS}

The occurrence of an unusually slipped clip (described below in the results section) urged this investigation. We evaluated all patients who had middle cerebral artery (MCA) bifurcation aneurysms clipped at a single centre between years 2015 and 2016. After excluding the patients who died, the group consisted of 64 patients operated due to either a ruptured $(n=29)$ or an unruptured aneurysm $(n=35)$. Both the early postoperative $(<24 \mathrm{~h})$ computed tomography (CT) and the 1-year follow-up (mean 10.5; 5-18 months) CT angiography (CTA) scans were performed on a GE Lightspeed PRO16 CT scanner. Neck remnants, displaced clips or new aneurysms were the key endpoints evaluated on CTA. If the clip was located by the dura in a postoperative exam, we refer to it herein as 'clip-to-dura adherence.' Digital image processing software was used for imaging analyses (RadiAnt v. 4.2.1, Medixant, Poland). Sex, age, subarachnoid haemorrhage presence, side and size of the aneurysm, operating neurosurgeon, surgeon who closed the dura and skull, total number of
Table 1. The characteristics of patients, aneurysms, neurosurgeons and clip types (case series)

\begin{tabular}{|c|c|}
\hline Parameters & $\begin{array}{l}\text { Number; } \% ; \text { mean } \pm \text { standard } \\
\text { deviation; median (range) }\end{array}$ \\
\hline Sex (male / female) & $18 ; 28.1 \% / 46 ; 71.9 \%$ \\
\hline SAH & $29 ; 45.3 \%$ \\
\hline \multicolumn{2}{|l|}{ MCA bifurcation aneurysm size: } \\
\hline Small & $46 ; 71.9 \%$ \\
\hline Medium & $8 ; 12.5 \%$ \\
\hline Large & $3 ; 4.7 \%$ \\
\hline Giant & $7 ; 10.9 \%$ \\
\hline Aneurysm side (left/right) & $26 ; 40.6 \% / 38 ; 59.4 \%$ \\
\hline $\begin{array}{l}\text { Aneurysms clipping procedures } \\
\text { performed by second author (XX) }\end{array}$ & $54 ; 84.4 \%$ \\
\hline $\begin{array}{l}\text { Dura closures performed by } \\
\text { first author (YY) }\end{array}$ & $39 ; 60.9 \%$ \\
\hline $\begin{array}{l}\text { Surgery performed together } \\
\text { by both authors ( } X X \text { and } Y Y)\end{array}$ & $37 ; 58.7 \%$ \\
\hline \multicolumn{2}{|l|}{$\begin{array}{l}\text { Total number of used permanent } \\
\text { clips: }\end{array}$} \\
\hline 1 & $37 ; 57.8 \%$ \\
\hline 2 & $21 ; 32.8 \%$ \\
\hline 3 & $3 ; 4.6 \%$ \\
\hline 4 & $1 ; 1.6 \%$ \\
\hline 5 & $1 ; 1.6 \%$ \\
\hline 8 & $1 ; 1.6 \%$ \\
\hline \multicolumn{2}{|l|}{ Types of aneurysm clips: } \\
\hline Straight & $34 ; 53.1 \%$ \\
\hline Curved & $29 ; 45.3 \%$ \\
\hline Angled & $4 ; 6.25 \%$ \\
\hline Bayonet & $7 ; 10.9 \%$ \\
\hline Fenestrated & $10 ; 15.6 \%$ \\
\hline Size of the longest clip [mm] & $7.4 \pm 3.0 ; 7.0(3.0-20.0)$ \\
\hline Age [years] & $57.4 \pm 10.8 ; 57.5(30-88)$ \\
\hline
\end{tabular}

MCA — medial cerebral artery; SAH — subarachnoid haemorrhage

applied permanent clips, their size and shape were evaluated (Table 1).

\section{Statistical analysis}

Standard statistical methods were applied in assessing the relation of these factors to clip-to-dura distance: $\chi^{2}$ or its nonparametric equivalents for categorical values, $t$ or Mann-Whitney $U$ tests for numerical values. Multivariate analysis was performed by means of logistic regression. Probability values of 


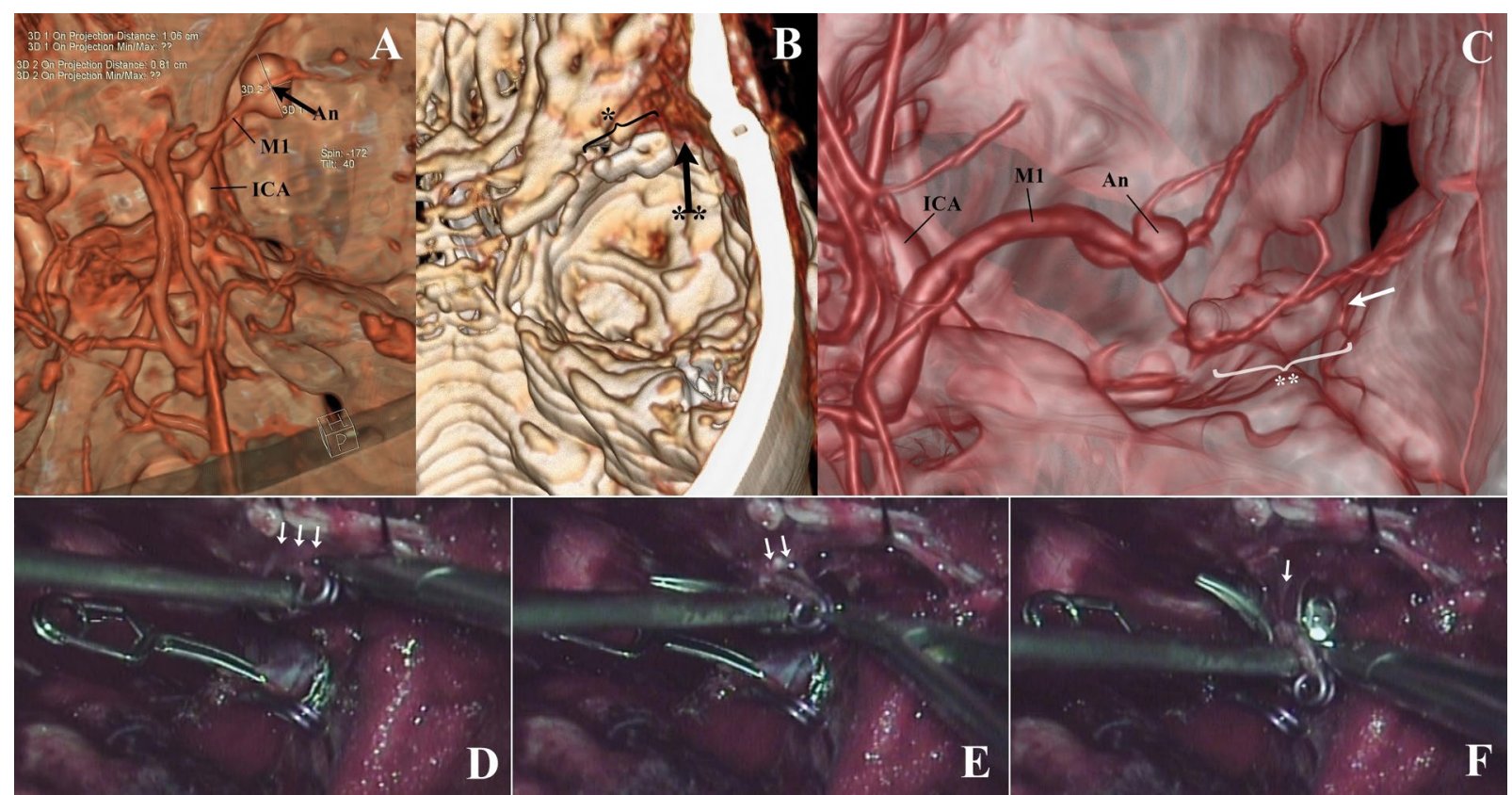

Figure 1. A case of clip slippage from an middle cerebral artery (MCA) aneurysm; A. Computed tomography (CT) angiography (CTA) demonstrating right MCA bifurcation aneurysm (arrow); B. Three-dimensional reconstruction of postoperative CT. A clip $\left({ }^{*}\right.$ ) appeared in direct contact with the dura (arrow), which was not regarded as an unusual finding; C. Routine 1-year follow-up CTA revealed a recurrent MCA aneurysm (An). The clip $\left({ }^{*}\right)$ located near the dura but separately from the aneurysm (arrow); D-F. Following stages of the clip excision together with a part of adhering dura. Although the coil was trapped in the former dural incision line, any sutures did not get across the coil. The aneurysm was secured with two clips beforehand. ICA — internal carotid artery; M1 — first segment of MCA.

$<0.05$ determined statistical significance. Statistica v. 9.0 (StatSoft Co, Tulsa, OK; USA) and Prism (GraphPad Software, La Jolla, CA; USA) were the software used in the study. IRB Committee in the institution is not required for retrospective studies.

\section{RESULTS}

The case of slipped clip

A 57-year-old female with an incidentally diagnosed $10 \mathrm{~mm}$-in diameter unruptured aneurysm of the MCA bifurcation. One curved $7 \mathrm{~mm}$ blade clip (Yasargil titanium clip, Aesculap AG, Tuttlingen, Germany) was applied along the aneurysm neck by standard pterional craniotomy. Without any graft or sealant, 3.0 silk single running suture was used for the dura. The $24 \mathrm{~h}$ postoperative and discharge CT did not reveal any complications, although the head of the clip was adjacent to the dura mater. The postoperative period was uneventful, though due to an unknown reason a postoperative digital subtraction angiography or CTA was not done. One year later the routine follow-up CTA revealed recurrent right MCA M1/M2 bifurcation aneurysm. Although endovascular approach was considered first, the final decision was to reoperate. It was revealed that the clip migrated away from the aneurysm sac and the spring coil firmly adhered to the dura in the location of previous suture line. The iatrogenic suturing during the initial operation or clip insertion into the gap in the suture line were either suspected, though could not be unequivocally confirmed (Fig. 1).

\section{Own series analysis}

Except for the case described above, the retrospective evaluation of 64 CTA exams did not reveal any other slipped clips. Aneurysm neck remnant was exhibited in 4 (6.3\%) cases following the clipping of two giant, one large and one small aneurysm, which required additional endovascular coiling.

The mean clip-dura distance in CT was $7.0 \mathrm{~mm}$ and did not exceed $26 \mathrm{~mm}$. In multivariate analysis none of the examined factors determined this distance in CT or CTA. The clip-to-dura distance measured in the follow-up CTA differed from that in the early ( $<24 \mathrm{~h}$ ) postoperative CT in $83.8 \%$ of cases and decreased by an average of $0.5 \mathrm{~mm}$ (Table 2, Fig. 2).

In every fifth patient (21.9\%; 15 of 64) a clip head or spring coil was touching the dura in the early postoperative CT. Multivariate analysis revealed that only the application of a fenestrated-shape clip correlated 
Table 2. Factors influencing the clip-to-dura distance and adherence in univariate analyses

\begin{tabular}{|c|c|c|c|c|c|}
\hline Factor & & $\begin{array}{l}\text { Coil of the clip adhered } \\
\text { to the dura } \\
\text { Number; \% of the group }\end{array}$ & $\mathbf{P}$ & $\begin{array}{c}\text { Clip-to-dura } \\
\text { distance [mm] } \\
\text { Mean } \pm \text { SD }\end{array}$ & $\mathbf{P}$ \\
\hline \multirow[t]{2}{*}{ Clip slippage } & Yes & $1 / 1 ; 100.0 \%$ & 0.07 & $0.0 \pm 0.0$ & 0.26 \\
\hline & No & $14 / 63 ; 22.2 \%$ & & $7.2 \pm 6.3$ & \\
\hline \multirow[t]{2}{*}{ Neck remnant occurrence } & Yes & $2 / 4 ; 50.0 \%$ & 0.20 & $5.3 \pm 7.5$ & 0.55 \\
\hline & No & $13 / 60 ; 21.7 \%$ & & $7.2 \pm 6.3$ & \\
\hline \multirow[t]{2}{*}{ Sex } & Males & $4 / 18 ; 22.2 \%$ & 0.89 & $6.8 \pm 5.9$ & 0.83 \\
\hline & Females & $11 / 46 ; 23.9 \%$ & & $7.2 \pm 6.6$ & \\
\hline \multirow[t]{2}{*}{ SAH } & Yes & $8 / 29 ; 27.6 \%$ & 0.48 & $7.3 \pm 6.5$ & 0.80 \\
\hline & No & $7 / 35 ; 20.0 \%$ & & $6.9 \pm 6.3$ & \\
\hline \multirow[t]{2}{*}{ Aneurysm size } & Small/medium & $12 / 54 ; 22.2 \%$ & 0.59 & $7.5 \pm 6.4$ & 0.26 \\
\hline & large/giant & $3 / 10 ; 30.0 \%$ & & $5.0 \pm 5.4$ & \\
\hline \multirow[t]{2}{*}{ Aneurysm side } & Left & $4 / 26 ; 15.4 \%$ & 0.21 & $8.0 \pm 6.0$ & 0.32 \\
\hline & Right & $11 / 38 ; 29.0 \%$ & & $6.4 \pm 6.5$ & \\
\hline \multirow{2}{*}{$\begin{array}{l}\text { Aneurysm clipping procedure performed } \\
\text { by the senior author }\end{array}$} & Yes & $14 / 54 ; 25.9 \%$ & 0.27 & $6.4 \pm 6.1$ & 0.04 \\
\hline & No & $1 / 10 ; 10.0 \%$ & & $10.7 \pm 6.4$ & \\
\hline \multirow{2}{*}{$\begin{array}{l}\text { Dura closure performed by the } \\
\text { first author (resident) }\end{array}$} & Yes & $11 / 39 ; 28.2 \%$ & 0.26 & $5.5 \pm 5.1$ & $<0.01$ \\
\hline & No & $4 / 25 ; 16.0 \%$ & & $9.7 \pm 7.3$ & \\
\hline \multirow[t]{2}{*}{ Surgery performed together by both authors } & Yes & $11 / 37 ; 29.7 \%$ & 0.16 & $5.4 \pm 5.2$ & $<0.01$ \\
\hline & No & $4 / 27 ; 14.8 \%$ & & $9.5 \pm 7.0$ & \\
\hline \multirow[t]{2}{*}{ Total number of permanent clips } & 1 & $5 / 37 ; 13.5 \%$ & 0.03 & $6.5 \pm 6.9$ & 0.56 \\
\hline & More than 1 & $10 / 27 ; 37.0 \%$ & & $7.5 \pm 5.9$ & \\
\hline \multirow[t]{10}{*}{ Shapes of aneurysm clips } & Straight & $9 / 34 ; 26.5 \%$ & 0.54 & $6.5 \pm 6.2$ & 0.45 \\
\hline & Other & $6 / 30 ; 20.0 \%$ & & $7.7 \pm 6.5$ & \\
\hline & Curved & $4 / 29 ; 13.8 \%$ & 0.10 & $8.6 \pm 6.1$ & 0.08 \\
\hline & Other & $11 / 35 ; 31.4 \%$ & & $5.9 \pm 6.3$ & \\
\hline & Angled & $0 / 4 ; 0.0 \%$ & 0.25 & $13.3 \pm 9.6$ & 0.04 \\
\hline & Other & $15 / 60 ; 25.0 \%$ & & $6.7 \pm 5.9$ & \\
\hline & Bayonet & $2 / 7 ; 13.3 \%$ & 0.73 & $7.0 \pm 5.8$ & 0.97 \\
\hline & Other & $13 / 57 ; 22.8 \%$ & & $7.1 \pm 6.4$ & \\
\hline & Fenestrated & $6 / 10 ; 60.0 \%$ & $<0.01$ & $3.3 \pm 5.8$ & 0.04 \\
\hline & Other & $9 / 54 ; 16.7 \%$ & & $7.8 \pm 6.2$ & \\
\hline \multirow[t]{4}{*}{ Age [years] } & $\leq 65$ & $3 / 17 ; 17.7 \%$ & 0.51 & $6.9 \pm 6.4$ & 0.70 \\
\hline & $>65$ & $12 / 47 ; 25.5 \%$ & & $7.6 \pm 6.3$ & \\
\hline & $\begin{array}{l}\text { The coil } \\
\text { of the clip } \\
\text { adhere to }\end{array}$ & $\begin{array}{l}\text { The coil of the clip } \\
\text { do not adhere } \\
\text { to the dura }\end{array}$ & $\mathbf{P}$ & $\begin{array}{c}\text { Clip-to-dura } \\
\text { distance } \\
\text { [mm] }\end{array}$ & \\
\hline & $\begin{array}{c}\text { the dura } \\
\text { Mean } \pm \text { SD }\end{array}$ & Mean \pm SD & & $r$ & $\mathbf{P}$ \\
\hline Age [years] & $54.6 \pm 13.6$ & $57.9 \pm 9.9$ & 0.31 & 0.09 & 0.44 \\
\hline Size of the longest clip [mm] & $8.6 \pm 4.6$ & $7.0 \pm 2.3$ & 0.08 & -0.25 & 0.05 \\
\hline Total number of permanent clips [n] & $2.4 \pm 1.9$ & $1.4 \pm 0.7$ & $<0.01$ & -0.13 & 0.30 \\
\hline
\end{tabular}

SD — standard deviation; SAH — subarachnoid haemorrhage

with clip-dura adherence in the $\mathrm{CT}$ (odds ratio [OR] 7.5; 95\% confidence interval [CI] 1.8-32.1). Next, we analysed the operative video records of a subgroup of 15 patients with clip adhesion to the dura and in nearly all cases (14/15) the permanent clip protruded over the Sylvian fissure (Fig. 3). 


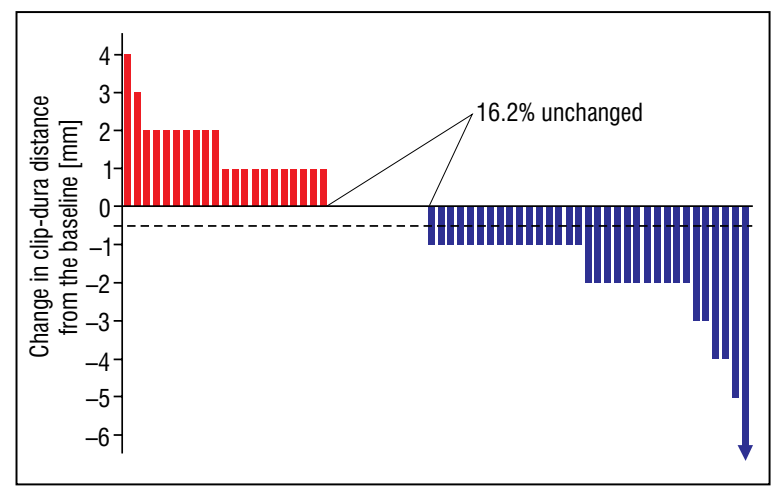

Figure 2. Waterfall plot highlighting changes in the clip-to-dura distance between an early postoperative computed tomography and 1 -year post-op computed tomography angiography. Red columns depict increases and blue decreases of this distance. The clip-dura distance shortened and lengthened in 33 and 21 cases, respectively. Dashed line denotes mean change.

\section{DISCUSSION}

Our case of a clip found in the dural suture certainly urged us to investigate the clip slippage phenomena. We hypothesized that clip slippage in early postoperative course was followed by the impaction of a part of the clip into the dural suture gap by the brain returning to its shape. Interestingly, the expanding brain in the postoperative period has been once hypothesized for a total clip slippage [20]. Although suturing of the clip's spring coil remains unconvincing unless the histopathology examination of the tissue adhering to the clip is performed.

To avoid potential clip slippage, two authors advised placing a small piece of the dura between the spring and sphenoid $[15,24]$. One author intentionally sutured the applied clip to the nearest dura in order to avoid neural compression from the clip [18]. Unlike in our case, dural adhesions or iatrogenic suturing were not reported to influence the clip displacement in the previous reviews $[4,5]$. We therefore hypothesized that this complication might be due to the shortcomings of our surgical technique and analysed the entire own series of similar MCA aneurysms. Review of those patients' CT exams confirmed that the direct contact with dura was observed in $>20 \%$ of patients. Statistical analysis revealed that clip adherence to the dura was not the reason of clip slippage and resulted from the applied clip type. The analysis of operative videos confirmed that in almost every case the clip seen by the dura in the postoperative $\mathrm{CT}$ protruded over the Sylvian fissure. That observation was not mentioned
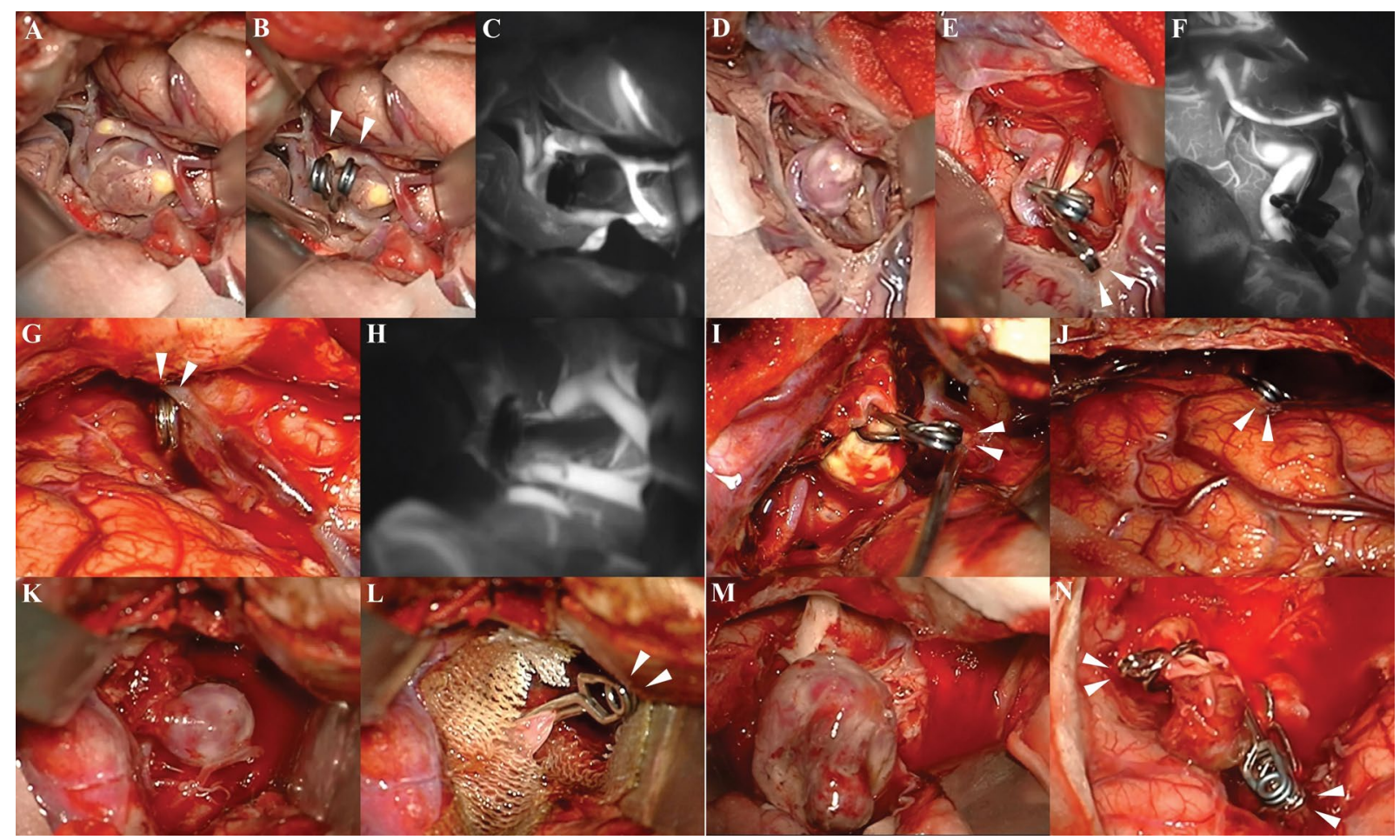

Figure 3. Intraoperative images portraying a clip bulging over the Sylvian fissure (arrows). Six random patients underwent clipping of middle cerebral artery bifurcation aneurysms (patient 1: A-C, patient 2: D-F, patient 3: G-H, patient 4: I-J, patient 5: K-L, patient 6: M-N). Intraoperative indocyanine green videoangiography confirmed proper clip position (cases $1-3)$. The screenshots of large $(A, D, K)$ and giant $(M)$ aneurysms prior to their clipping were shown. 


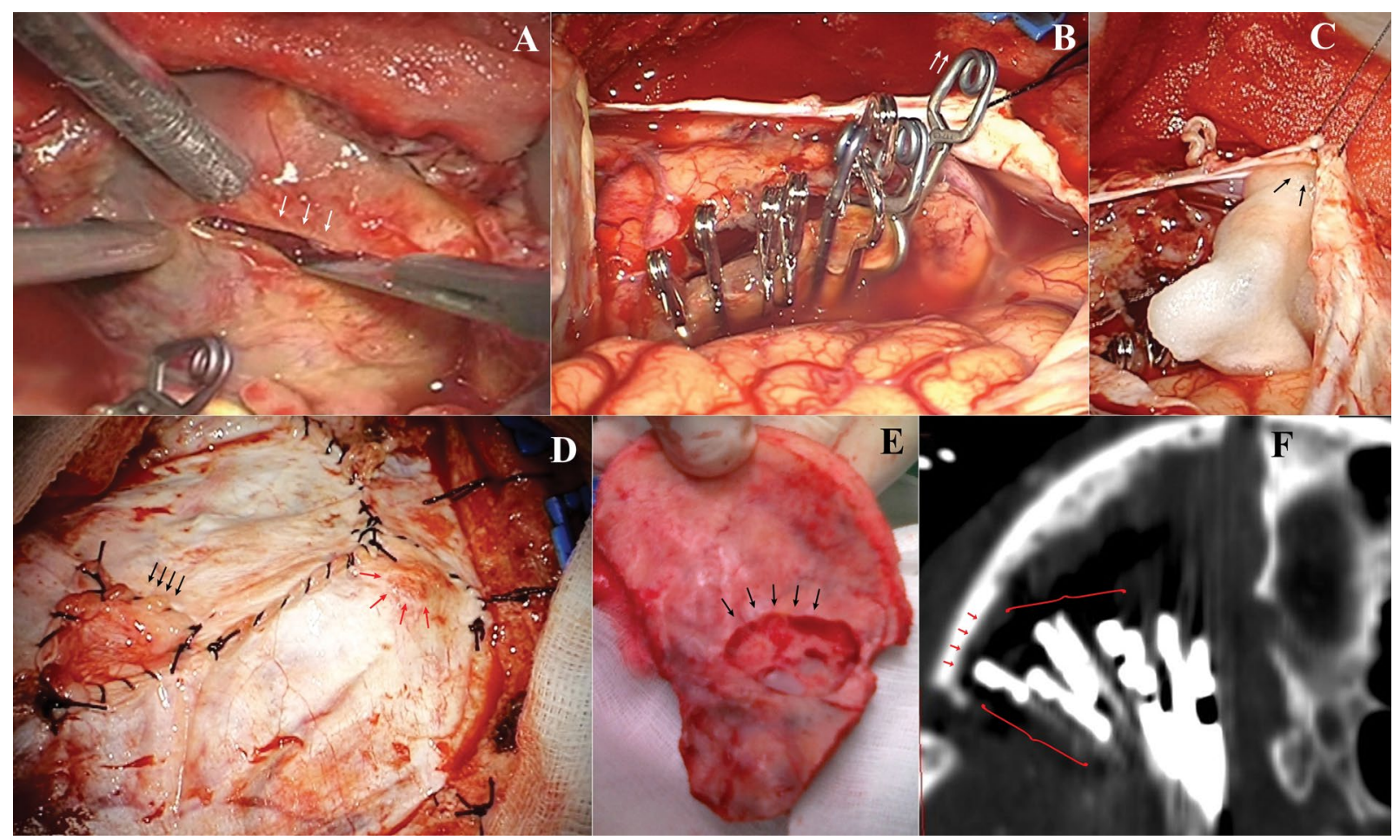

Figure 4. Several solutions to prevent clip bulging into a suture gap; $\mathbf{A}$. Dome of a giant middle cerebral artery bifurcation aneurysm was incised (arrows) and debulked; B. A tandem of clips (arrows) protruded over the brain surface, the closure of the dura and the skull needed a modification; C. A sponge (arrows) was used to separate the clips from the dura; $\mathbf{D}$. The transposition of dural flaps required the team to reconstruct the dura (arrows); E. The inner table of bone flap was drilled (arrows) to make more room for clips; F. Stack of clips \{\} in the postoperative computed tomography, reconstructed bone (arrows).

in the literature at all. Our study therefore suggests that clip touching the dura in the CT should not be regarded as an abnormal finding.

In the 1970's Drake insisted that angiography should be performed soon after surgery as well as repeated after a week [7]. At our department angiography was not routinely performed after operating on an unruptured aneurysm, but only in case of any problems encountered during securing the aneurysm or if the neurosurgeon was not certain of the clip's position. For the same reasons, postoperative angiography was not performed in our case of clip slippage.

On the other hand, the case of a clip trapped into the dural suture emphasizes that reapproximating the dura over the clip remnants is the crucial manoeuvre. Regarding MCA aneurysms, Apuzzo [1] suggested to make the dural incision far posteriorly, although not to avoid further conflict of the clip and the dura but to increase the access to the aneurysm. Hayashi et al. [12] speculated that the clip slipped due to its trapping between optic nerves. Another study described a slipped clip that caused the aneurysm to rupture when releasing the retracting spatulas [6]. However, there is no mention in the literature that a protruding clip may be impacted in the dural suture. Such possibility justifies tight suturing of the dura or planning the dural incision out of the underlying Sylvian fissure, as stated by Apuzzo [1]. Whenever required, a long clip or a tandem of clips should be applied and special attention should be paid to closing the dura afterwards. We propose several solutions to overcome problems with clip protrusion above the brain surface: planning the incision line out of the Sylvian fissure, tightly suturing the dura (avoid gaps, preferably to be done by an experienced surgeon [12]), using an artificial material to separate the clip, increasing the entire size of the dural flap and if required, drilling the inner table of a bone flap (Fig. 4).

Authors provided numerous explanations for the unintended clip displacement. Repetitive intraoperative opening and closing notably reduces the clip's closing forces [4, 5, 23]. Some blamed the scissoring effect of a long clip or related clip failure to old generation of clips $[2,10,13,14]$. An increase of the systolic arterial blood pressure can push off the clip blades of the aneurysm sac $[7,9,22]$. Out of the 
above, the incomplete clipping, use of insufficient amount of clips on a giant aneurysm as well as a broad or calcified neck of the aneurysm seem to be the most common reasons for postoperative clip slippage. Interestingly, the statistical analysis of the entire pooled cohort did not confirm that these factors are responsible for the degree of clip displacement. The analysis demonstrated that opposite to applying a stack of clips, choosing a single clip may be attributed to the aneurysm recurrence. Tandem clipping or using a booster clip is proved by others to be more durable solution [10, 19, 21, 25]. Moreover, the greater the gap between the blades of the clip is the greater force is required to its displacement [5].

The previously-clipped aneurysm in which the clip migrated away pose a surgical challenge. We encountered problems with adhesions surrounding the old clip which were difficult to release safely. Our experiences with re-clipping of other recurrent aneurysms support the well-known suggestion that if possible, the old clip should be left in the scar. Otherwise a variety of endovascular techniques could be successfully used in these patients [3].

\section{CONCLUSIONS}

In summary, any unusual complication, such as a slipped clip from an apparently correctly secured aneurysm, should be followed by an audit of own series and confronted to others' findings. The case of slipped clip that trapped into the dural suture was not found in our own series or in the literature. Based on our results we demonstrated that the clip positioned by the dura is a normal finding in the postoperative CT scan. We additionally concluded that the surgeon should consider MCA aneurysm recurrence when a single clip is used.

\section{Acknowledgements}

As James A. Froude claimed "experience teaches slowly and at the cost of mistakes," the first author wishes to thank the senior author for his continuous mentorship.

\section{REFERENCES}

1. Apuzzo ML. Brain surgery: complication avoidance and management. Churchill Livingstone. 1993: 988.

2. Asgari S, Wanke I, Schoch B, et al. Recurrent hemorrhage after initially complete occlusion of intracranial aneurysms. Neurosurg Rev. S. Asgari, Department of Neurosurgery, University Hospital, 45147 Essen, Germany. 2003; 26(4): 269-274.

3. Beltagy $M$, Muroi $C$, Roth $P$, et al. Recurrent intracranial aneurysms after successful neck clipping. World Neurosurg. 2010; 74(4-5): 472-477, doi: 10.1016/j.wneu.2010.06.036, indexed in Pubmed: 21492597.
4. Carvi y Nievas MN, Höllerhage HG. Risk of intraoperative aneurysm clip slippage: a new experience with titanium clips. J Neurosurg. 2000; 92(3): 478-480, doi: 10.3171/jns.2000.92.3.0478, indexed in Pubmed: 10701539

5. Carvi y Nievas MN. Assessment of the clipping efficacy of intracranial aneurysms: analysis of the employed methodology in relation to case difficulty. Neurol Res. 2007; 29(5): 506-516, doi: 10.1179/016164107X164148, indexed in Pubmed: 17535574.

6. Diraz A, Kyoshima K, Kobayashi S. Dorsal internal carotid artery aneurysm: classification, pathogenesis, and surgical considerations. Neurosurg Rev. 1993; 16(3): 197-204, indexed in Pubmed: 8272208 .

7. Drake CG, Allcock JM. Postoperative angiography and the "slipped" clip. J Neurosurg. 1973; 39(6): 683-689, doi: 10.3171/ jns.1973.39.6.0683, indexed in Pubmed: 4759655.

8. Drake C, Peerless S, Hernesniemi J. Surgery of vertebrobasilar aneurysms. Vienna: Springer. 1996.

9. Drake CG, Vanderlinden RG. The late consequences of incomplete surgical treatment of cerebral aneurysms. J Neurosurg. 1967 27(3): 226-238, doi: 10.3171/jns.1967.27.3.0226, indexed in Pubmed: 6047996.

10. Giannotta SL, Litofsky NS. Reoperative management of intracrania aneurysms. J Neurosurg. 1995; 83(3): 387-393, doi: 10.3171/ jns.1995.83.3.0387, indexed in Pubmed: 7666212.

11. Giannotta S. Complication Avoidance for Large and Giant Carotid Ophthalmic Aneurysms. New Trends in Management of Cerebro-Vascular Malformations. Pasqualin A, Da Pian R, editors. Vienna: Springer. 1994: 198-202, doi: 10.1007/978-3-70919330-3 36.

12. Hayashi $Y$, Kimura M, Satake R, et al. Possible participation of clip rotation in the formation of de novo aneurysm. J Clin Neurosci. 2004: 11(3): 331-334, doi: 10.1016/S0967-5868(03)00199-1 indexed in Pubmed: 14975434.

13. Horiuchi T, Li Y, Seguchi T, et al. Clip blade scissoring with titanium bayonet clip in aneurysm surgery. Two case reports. Neurol Med Chir (Tokyo). 2012; 52(2): 84-86, doi: 10.2176/nmc.52.84, indexed in Pubmed: 22362289.

14. Kariyattil R, Panikar D. Scissoring of a Cobalt Alloy Aneurysm Clip causing Slippage during Cerebral Aneurysm Surgery: Case report and review of literature. Sultan Qaboos Univ Med J. 2013; 13(1): 179-182, indexed in Pubmed: 23573404.

15. Kataoka K, Arita N, Yamada Y, et al. Clipping techniques for the juxta-dural ring aneurysms. Surg Cereb Stroke. 1995; 23(1): 55-60, doi: 10.2335/scs1987.23.1 55

16. Kim YH, Kim JE, Kang HS, et al. Migration of an aneurysm clip to the sacral subarachnoid space. Acta Neurochir (Wien). 2009; 151(6): 699-700, doi: 10.1007/s00701-009-0260-2, indexed in Pubmed: 19277456.

17. McKissock W. Recurrence of an intracranial aneurysm after excision. J Neurosurg. 1965; 23(5): 547-548, doi: 10.3171/ jns.1965.23.5.0547, indexed in Pubmed: 5858447.

18. Mortazavi M, Ravanpay A, Sekhar L. Clipopexy: an anchoring technique to avoid compression of adjacent neurovascular structures by aneurysm clip: report of two cases. Cureus. 2014, doi: 10.7759 /cureus. 168 .

19. Nakamura K, Kitabayashi M, Murata T. Clipping for Wide-necked Asymptomatic Unruptured Intracranial Aneurysm. Surg Cereb Stroke. 2012; 40(4): 251-256, doi: 10.2335/scs.40.251.

20. Oyesiku NM, Jones RK. Migration of a Heifetz aneurysm clip to the cauda equina causing lumbar radiculopathy. Case report. J Neurosurg. 1986; 65(2): 256-257, doi: 10.3171/jns.1986.65.2.0256, indexed in Pubmed: 2941527.

21. Park CK, Shin HS, Choi SK, et al. Clinical analysis and surgical considerations of atherosclerotic cerebral aneurysms: experience of a single center. J Cerebrovasc Endovasc Neurosurg. 2014; 16(3): 247-253, doi: 10.7461/jcen.2014.16.3.247, indexed in Pubmed: 25340027.

22. Sato S, Suzuki J. Prognosis in cases of intracranial aneurysm after incomplete direct operations. Acta Neurochir (Wien). 1971; 24(4): 245-252, indexed in Pubmed: 5132408.

23. Szmuda T, Sloniewski P. Giant intracranial aneurysms - surgical treatment, accessory techniques and outcome. In: Murai Y, editor. Aneurysm. InTech. 2012. : 351-382.

24. Uemura T. Treatment of a postoperative iatrogenic aneurysm following repeated temporary clipping procedures and pitfalls of the angled fenestrated clip application. Surg Cereb Stroke. 1987; 15(3): 271-274, doi: 10.2335/scs1987.15.3 271.

25. Wester K. Lessons learned by personal failures in aneurysm surgery: what went wrong, and why? Acta Neurochir (Wien). 2009; 151(9): 1013-1024, doi: 10.1007/s00701-009-0452-9, indexed in Pubmed: 19609480. 